\title{
Eneias como representação do principium individuationis de Augusto
}

\author{
Douglas Esteves Moutinho ${ }^{\mathrm{i}}$
}

\begin{abstract}
Resumo: O período compreendido como Pax Romana, iniciado por Augusto, pode ser considerado como um dos momentos mais significantes da civilização romana. Nela teve início a Era de Ouro das artes em latim, tendo seu apogeu na literatura com a Eneida de Virgílio, poema que elogia o Império, o povo e seu representante máximo. Essa paz apenas foi possível graças a um conjunto de fatores, dentre eles a utilização da própria obra de Virgílio como propaganda. O trabalho em questão pretende analisar a obra e o momento histórico de sua composição, a fim de buscar os motivos inconscientes que possibilitaram à Eneida elogiar de maneira tão substancial o Princeps Civitatis, o qual ela retratava.
\end{abstract}

Palavras-chave: Augusto. Virgílio. Eneida. Eneias. Monomito.

\section{Aeneas as representation of Principium Individuationis of Augustus}

\begin{abstract}
The period of time understood by Pax Romana initialized by Augustus may be considered one of the most significant moments of the Roman civilization, in which began the Golden Age of the Roman Arts. In the literature, it had his zenith with Virgil's Aeneid, poem which praises the empire, the people and their highest representative. This peace was possible only thanks to a set of factors, among them the use of the Aeneid as propaganda. This paperwork intends to analyze the work and the historical moment of its composition in order to find the unconscious motives that made possible that the Aeneid praised so substantially the Princeps Civitatis which it portrayed.
\end{abstract}

Keywords: Augustus. Virgil. Aeneid. Aeneas. Monomyth.

Submetido em: 29 jan. 2020

Aprovado em: 21 jun. 2020

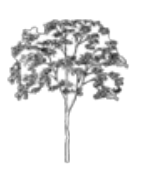

\author{
(cc) EY-SA \\ Esta obra está licenciada com uma Licença Creative Commons \\ Compartilha Igual 4.0 Internacional \\ DLCV - Língua, Linguística \& Literatura
}

ISSN 1679-6101

EISSN 2237-0900

\footnotetext{
${ }^{\text {i } U n i v e r s i d a d e ~ F e d e r a l ~ d o ~ R i o ~ d e ~ J a n e i r o ~-~ N I E L I M-U F R J . ~ E-m a i l: ~ d o u g m o u t i n h o @ g m a i l . c o m . ~}$
} 


\section{INTRODUÇÃO}

“A Eneida é a mais alta expressão da cultura do Século de Augusto, uma cultura que pretendia, é certo, dominar o mundo, mas também, como já sublinhámos mais de uma vez, pacique imponere morem ${ }^{1}$ ”. (PEREIRA, 2013, p. 324). Assim conclui Maria Helena da Rocha Pereira a primeira parte dos Estudos de história da Cultura Clássica: volume II Cultura romana. Tal conclusão, embora amplamente difundida, não deixa de apresentar lacunas em relação à amplitude de possibilidades analíticas necessárias, para a obra em questão servir de parâmetro para a explicação (resumo, ou paradigma) do momento histórico, no qual o poema é composto. A grande variedade de obras acerca do tema é cognoscível, no entanto, a abordagem mitológica e a psicanalítica são escassas nos estudos latinos, uma vez que a grande maioria dos autores aborda, sobretudo, o campo clássico grego, negligenciando muitas vezes as inúmeras possibilidades que os estudos relativos ao povo romano ${ }^{2}$ poderiam agregar. Autores como Marcel Detienne, Jean-Pierre Vernant e Pierre Vidal-Naquet, embora influenciadores e revolucionários nos estudos clássicos, voltaram grande parte de suas obras aos estudos gregos. Autores como Karl Galisnky, ainda que tenha realizado substanciais pesquisas, contemplou uma análise em grande parte social e cultural de Roma. Ainda assim, não podemos deixar de reconhecer a suma importância de seus estudos acerca da obra de Virgílio e do Século de Augusto. Estabelece-se, assim, uma lacuna nos estudos clássicos, abordar o mito e o momento histórico através de uma perspectiva psicológica ${ }^{3}$.

Para trazermos à discussão uma outra proposta de abordagem da obra virgiliana, sem, contudo, nos esquecermos dos estudos já canônicos de autores consagrados, apresentamos uma proposta junguiana e campbelliana, buscando compreender os motivos relacionados aos caminhos percorridos por Augusto e Eneias, objetivando encontrar as razões que possibilitaram a obra de Virgílio alcançar tamanho sucesso, espelhando o modelo ideológico e

\footnotetext{
${ }^{1}$ Impor a paz à sua maneira

2 O termo "povo" (populus romanus) deve ser entendido como um grupo de pessoas, que, no período do principado, habitava a cidade de Roma e compartilhava o respeito pela traditio (tradição) e pelo mos (costume). Durante o período de César e de Augusto, a imagem do representante de Roma passava a personificar a vontade do povo romano. Ambos os representantes exaltavam em seus discursos a "glória do povo romano", fazendo, dessa forma, que suas ações fossem assimiladas à vontade deste. O povo romano e seu líder tornavam-se um nesses discursos. (DORNELES, 2018, p. 56). Tal concepção diferencia-se da ideia de "povo" vigente durante o período republicano, no qual ele podia ser compreendido como "conjunto das pessoas nascidas em Roma que tinham algum poder de mando (patrícios)” (DIREITO, 2014, p. 188), tal como da utilização da palavra em períodos imperiais posteriores, em que "povo" designava cidadãos romanos (status civitatis). Este status poderia ser adquirido naturalmente através do nascimento em território romano (ius soli) ou pela nacionalidade dos pais (ius sanguinis). Estrangeiros (peregrinos e latinos) podiam ser feitos cidadãos romanos pelo benefício da lei ou vontade imperial, pela naturalização ou pela manumissão. (DIREITO, 2014, p. 187).

${ }^{3}$ Entende-se “psicológico” nesse contexto também como “mitológico”.
} 
que se queria exemplar do principado augustano. Vale ressaltar, que o presente trabalho não parte da premissa de afirmar que a Eneida foi a causa do sucesso de Augusto, nem o caminho inverso, apontando a obra literária como consequência dele. Ambas aconteceram em momentos simultâneos e se entrelaçam, quando as analisamos através da abordagem aqui proposta.

Eneias personifica o ciclo cosmogônico de herói apresentado por Joseph Campbell em sua célebre obra As mil faces do herói, ciclo esse que, de acordo com as teorias da psicologia analítica de Jung e do monomito do próprio Campbell, configuram o ciclo anímico o qual o ser humano deve transpassar, a fim de alcançar a sua forma mais plena, ou seja, passar pelo principium individuationis ${ }^{4}$ até atingir o selbst ${ }^{5}$. Augusto transmite que passara por esse processo enquanto representado no herói, demonstrando em sua apoteose e em sua missão civilizadora aspectos sobre-humanos referentes a alguém que já transpassara a barreira do humano para o divino, a mesma barreira que separa o herói dos poemas clássicos dos padrões humanos convencionais.

A sociedade precisa de heróis, "porque ela tem necessidade de uma constelação de imagens suficientemente poderosa para reunir, sob uma mesma intenção, todas essas tendências individualistas. [...] A nação necessita, de algum modo, de uma intenção, a fim de atuar como um poder uno.” (CAMPBELL, 2017, p. 142). Eneias, antes de ser um herói literário das obras de Virgílio, é um herói lendário, um herói lendário de Roma, e, como tal, é o responsável por criar algo novo. "Um herói lendário geralmente é o fundador de algo, o fundador de uma nova era, de uma nova religião, uma nova cidade, uma nova modalidade de vida. Para fundar algo novo, ele deve abandonar o velho e partir em busca da ideia-semente, a ideia germinal que tenha a potencialidade de fazer aflorar aquele algo novo.” (CAMPBELL, 2017, p. 143).

\section{A ENEIDA}

Antes de nos atermos à obra em si, vale repensar o gênero a qual ela pertence, gênero esse muitas vezes condensado e diminuído a uma narrativa com heróis. O épico como gênero literário realmente apresenta diversas acepções, mas em todas há algo que o unifica em algo maior: a memória coletiva (GRIMAL, 1992, p. 185). Eneias não é um personagem criado por

\footnotetext{
${ }^{4}$ Princípio de individuação: “A finalidade da evolução psicológica é tal, como na evolução biológica, a autorealização, ou seja, a individuação.” (JUNG, 2013, p. 25).

${ }^{5} \mathrm{O}$ estágio mais elevado da mente, a união plena entre consciente e inconsciente, atingido através do processo de individuação. (JUNG, 2014, p. 32).
} 
Virgílio, mas uma representação de algo maior, algo que detinha o poder de unir as pessoas daquele determinado espaço geográfico, não apenas o que era entendido como Roma, mas os muitos povos latinos que compartilhavam o mesmo solo, que na época de Augusto se tornara o Império Romano. Não podemos deixar de nos ater ao fato de que no próprio momento abordado pela Eneida, compartilhavam aquele solo rútulos, latinos, volscos, árcades, entre outros povos. Estes estão presentes na obra, e Eneias atua como um elo que os unifica, estabelecendo assim certa identidade comum e sendo o elemento civilizador daquela região unificada. Eneias era uma lenda 6 , pertencia à memória coletiva de "tribos" que compartilhavam um mesmo substrato cultural, e que mais tarde se fundiriam em uma civilização com maior complexidade. Embora o personagem seja lendário, representa um movimento histórico. (GRIMAL, 1992, p. 207).

O gênero épico, como exemplificado na obra de Virgílio, é a contextualização de seu herói, herói que já estava presente em cultos e que através do poeta representaria o movimento - ou missão - civilizador que Augusto almejava. Era então fundamental a condensação cultural daquilo que era por ele governado. A consolidação do Imperium Romanum $^{7}$ em uma entidade muito mais unificada do que uma coleção de províncias era o movimento mais importante da época, segundo Karl Galiski (apud PEREIRA, 2013, p. 229). Nada então mais natural que ser representado por aquilo que une o(s) povo(s), aquilo que era digno de tamanho orgulho histórico-coletivo. Augusto converteu-se no próprio herói, aquele que fora preparado para tal, aquele que havia alcançado sua plenitude, e assim tornara-se sobre-humano; estava presente nas grandes epopeias, dividindo o espaço com Hércules e Aquiles, e tal como eles, descendia de divindades. Augusto transformou-se no arquétipo ${ }^{8}$ do selbst finalmente alcançado, ao passar pelos mesmos caminhos do Eneias, seu ascendente.

\section{ENEIAS E AUGUSTO ${ }^{9}$}

A epopeia, ou o épico, era tão distinta, que fazia parte do discurso lógico, era declamada e não cantada, composta por um ritmo contínuo - o que a diferenciava das tragédias, dramas ou comédias - tamanha era a lógica da obra, que nos séculos finais do império, era questionado se Virgílio fora um poeta ou um retórico (GRIMAL, 1992, p. 186).

\footnotetext{
${ }^{6}$ Não entraremos aqui no âmbito da fundamentação da lenda como advinda de fatos históricos ou não.

${ }^{7}$ Império Romano.

8 "Os conteúdos do inconsciente pessoal são principalmente os complexos de tonalidade emocional, que constituem a intimidade pessoal da vida anímica. Os conteúdos do inconsciente coletivo, por outro lado, são chamados arquétipos.” (JUNG, 2014, 12)

${ }^{9}$ Todas as citações em português da Eneida são de autoria de Carlos Alberto Nunes (2016).
} 
Era então evidente a eficácia das palavras do autor, uma vez que fossem naquele tempo consideradas relevantes. Graças a Virgílio, os romanos tomavam consciência do seu lugar no espaço e da missão que a eles fora confiada. No emblemático Canto VI, Anquises assim profere:

\author{
Aonde arrastais-me sem fôlego, Fábios? Sozinho - és o Máximo, \\ ganhando tempo, tu salvas, quase perdida, a República. \\ Outros, é certo, hão de o bronze animado amolgar com mão destra, \\ ninguém o nega; do mármore duro arrancar vultos vivos, \\ nos tribunais falar bem, apontar com seu rádio as distâncias \\ na azul abóbada e os astros marcar quando a leste despontam. \\ Mas tu, romano, aprimora-te na governança dos povos. \\ Essas serão tuas artes; e mais: leis impor e costumes, \\ poupar submissos e a espinha dobrar dos rebeldes e tercos. (VI, v. 845-853).
}

A catábase estava previamente anunciada por passagens anteriores ao canto VI. No Canto III, Heleno profetiza a Eneias que o herói deveria rumar a Sicília para ter sucesso na Itália; no Canto V, o próprio fantasma de Anquises o adverte de que deveria ir com Sibila ao Averno, a fim de o consultar. O fatum ${ }^{10}$ estava guiando os acontecimentos mitológicos, assim como estava agindo, a fim de favorecer a elevação de Augusto. O canto VI representa um importante momento do poema, pois a catábase de Eneias é de grande relevância para todo o poema. Destinado ao poder através da linhagem de Assácaro, dos Dárdanos - segundo o Hino Homérico a Afrodite -, Eneias recebe naquele momento de Anquises a homologação de sua função como pater familias $^{11}$, requisito indispensável para ser edificador das bases futuras de Roma. Essa homologação, segundo Alcione Lucena Albertim, representa também a paternidade de Augusto em relação ao Império, sobretudo quando se torna pontifex maximus $^{12}$. (ALBERTIM, 2008, p. 8). Em suma, o canto VI é o canto que associa Augusto a Eneias, apresentando o mesmo como detentor dos principais valores romanos, aqueles que seriam o tripé da sociedade: uirtus ${ }^{13}$, pietas ${ }^{14}$ e fides ${ }^{15}$. Outrossim, Virgílio apresenta ao povo a fórmula do Império tal qual Augusto acabara de fundar, já que, conforme Grimal (1992, p. 234), “o imperialismo de Roma não consiste, como no tempo de Verres, em pilhar os súditos, mas em estabelecer uma lei que garanta a justiça e o direito.”

\footnotetext{
10 “destino".

${ }^{11}$ Mais elevado status familiar de Roma.

${ }^{12}$ A mais alta dignidade do culto romano. Augusto a atribuíra ao imperador.

13 “honra”. É digno de nota a diferença entre uirtus e honor. Honor é o conceito de honra exterior e uirtus a honra interior. (PEREIRA, 2013, p. 405).

14 “A pietas define-se habitualmente como um sentimento de lealdade para com aqueles a quem o homem está ligado por natureza (pais, filhos, parentes)”. (PEREIRA, 2013, p. 338).

${ }^{15}$ Fidelidade ao juramente (palavra) e às divindades. (PEREIRA, 2013, p. 335).
} 
Outro aspecto interessante acerca da forma do poema é sua composição em doze cantos, metade da extensão da Ilíada, e ainda assim, dividida em duas partes. O Canto VI serve como um divisor para a obra, delimitando aquilo que é assimilado à Odisseia nos seis primeiros cantos, e à Ilíada nos seis últimos. Na primeira parte vemos o herói vagando em águas misteriosas, amores e a descida ao mundo dos mortos, conteúdos que nos remetem à Odisseia, enquanto na segunda parte, contemplamos um contexto de guerras e mortes. Mais uma vez deparamo-nos com os interesses de Augusto sendo explícitos nos versos de Virgílio. O Saeculum Augustum ${ }^{16}$ abrange dois momentos cruciais da história romana. Um deles, as batalhas contra os assassinos de César e depois disso contra Marco Antônio, em que o futuro imperador obteve vitória na batalha do Áccio (elogiada no canto VIII da Eneida); outro momento, posterior, aquele que foi estabelecido como Pax Romana ${ }^{17}$ - ou Paz de Augusto. Augusto se provara detentor de poder e controle em ambos os momentos. Tal como Eneias, que no decorrer do poema se atém a um processo de personificação da cidade romana, Augusto não tem seu caráter comprometido, continuando imutável, condição essencial para um governante romano, uma vez que tanto em momentos de guerra como em épocas de paz, os cidadãos deveriam se comportar de forma correspondente ao presente momento, mas mantendo seu caráter. Augusto novamente tornara-se o modelo ideal a ser seguido.

Embora as afinidades entre Eneias e Augusto fossem inúmeras, nada disso seria tão eficaz se não houvesse uma ligação entre Augusto e os deuses. Era essencial para os interesses do novo império, que Augusto fosse nobre e divino. Exemplificando de forma precisa, Pierre Grimal, em sua obra Virgílio ou o segundo Nascimento de Roma, tece essa linha genealógica desde os tempos de Tróia:

[...] na origem estava a fundação de Tróia, a vinda de Dárdano, chegado de Cortona, a terras estruscas, para ir ao Oriente, onde o rei de Tróia, Teucro, o acolheu com benevolência e deu-lhe a mão de sua filha, Batéia. É verdade que Dárdano era filho de Zeus e Electra, por sua vez, filha de Atlas. Depois, a partir desse momento, desenrolava-se a genealogia que conduzia a César: Dárdano tinha um filho chamado Erictônio, que era pai de Tros, que engendrou Ilos e Assáraco. Este deu origem a Laomedonte [...]. De Laomedonte nasceu Príamo; de Assácaro nasceu Cápis, pai de Anquises e deste, unido a Afrodite, nasceu enfim Enéias. Genealogia perfeitamente satisfatória para os romanos do século I a.C., que ficavam felizes por não pertencerem a um ramo troiano que passava por Laomedonte e Príamo (o primeiro, traidor; o segundo, infeliz); mas por Assáraco e Anquises, que estavam livres da maldição lançada pelos deuses contra o outro ramo. (GRIMAL, 1992, p. 213).

\footnotetext{
${ }^{16} \mathrm{O}$ século de Augusto é o período que se inicia em 63 a.C. e vai até 14 d.C. (PEREIRA, 2013, p. 229).

${ }^{17}$ Período iniciado em 27 a.C. com a atribuição do título de “Augusto” ao imperador e terminado em 193 d.C. com a chegada ao poder da dinastia Severa.
} 
Eneias situa-se entre o divino e o humano, entre o consciente e o inconsciente, tal como Augusto, sendo o ideal herói da epopeia. Augusto passa assim a um ser sobre-humano, escolhido pelos deuses para governar, civilizar e trazer novamente para Roma sentido, costumes e valores. Em sua História de Roma, Grimal afirma que:

No decurso das guerras civis, Roma perdera muitas de suas tradições. Otávio compreendeu que era preciso dar-lhe outras novas. A empresa era difícil; ele se apoiou nos poetas, para criar verdadeiros “mitos”, a serviço de uma fé nova. Virgílio, redigindo a Eneida, deu ao novo senhor, mas também a sua pátria, o mais belo presente. Reuniu os elementos esparsos da velha lenda que unia os romanos - e muito particularmente Otávio, herdeiro de César - a raça dos deuses. Justificou ao mesmo tempo a conquista romana - voltando a dar "boa consciência" aos conquistadores - e a ditadura de fato estabelecida pelo vencedor de Áccio. Das suas mãos nascia como que uma nova forma do poder, que não era a realeza (desde os Idos de Março, não se tratava mais desse tema), mas conservava desta o caráter religioso e erguia o Senhor acima de sua simples condição mortal. Assim aparecia, em seus versos, o "piedoso Eneias", chefe militar e sacerdote, intérprete da vontade divina, marcado pelo Destino, invencível no campo de batalha e guia infalível na paz. (GRIMAL, 2010, p. 128).

Não podemos, no entanto, associar o sucesso de Augusto como imperador unicamente à Eneida. A ordem é inversa. Augusto consolida-se como imperador vencedor, um legítimo representante do império através de César. Uma época próspera surge, refletida na arquitetura, na religião e nas artes. O próprio Augusto influencia o florescimento da poesia, como assevera Maria Helena da Rocha Pereira:

Augusto restaurou oitenta e dois templos e erigiu novos (como o de Apolo Palatino), reconstrói o palácio de Pompeu, erige o de Marcelo, ergue uma nova cúria, abre o terceiro Fórum, repara vias, pontes, aquedutos. Esse período abriu as portas para o que foi conhecido nas artes como a época áurea do classicismo romano. Há uma renovação religiosa, com exclusão dos cultos orientais, consagração especial a Apolo (que considerava ligado à Gens Iulia), que erigiu um templo no Palatino. O grande florescimento artístico da época está na poesia, fortemente influenciado por Augusto. Suetónio escreve que ele "fomentou de todas as maneiras o talento do seu tempo”. (PEREIRA, 2013, p. 233).

\section{O MONOMITO}

“O percurso padrão da aventura mitológica do herói é uma magnificação da fórmula representada nos rituais de passagem: separação-iniciação-retorno que podem ser considerados a unidade nuclear do monomito. (CAMPBELL, 2007, 36) [...] O Herói [...] é o centro do mundo, o ponto umbilical através do qual as energias da eternidade irrompem no plano temporal. (CAMPBELL, 2007, p. 45). 
Assim descreve Joseph Campbell sua teoria, o monomito, que, como nos é apresentado pelo trecho correspondente, se debruça sobre a jornada do herói e como essa está intrínseca a toda grande história ou mito já contado. Vale ressaltar que o termo anteriormente já fora empregado por autores precursores a Campbell, com destaque para James Joyce, embora não desenvolvida como teoria. Campbell então se apropria de um termo já existente, que abarcaria toda a questão levantada pelo autor acerca da universalização do mito, tendo como premissa os estudos psicanalíticos teóricos e em campo.

Antes de abordarmos o monomito em si, exploraremos as raízes dessa abordagem, máxime a psicologia analítica - ou junguiana -, mais especificamente o inconsciente coletivo. Jung explica da seguinte maneira a utilização do termo "coletivo”, conjuntamente com um substrato psíquico universal.

Eu optei pelo termo "coletivo" pelo fato de o inconsciente não ser de natureza individual, mas universal; isto é, contrariamente à psique pessoal ele possui conteúdos e modos de comportamento, os quais são 'cum grano salis' os mesmos em toda parte e em todos os indivíduos. Em outras palavras, são idênticos em todos os seres humanos, constituindo, portanto, um substrato psíquico comum de natureza psíquica suprapessoal que existe em cada indivíduo. (JUNG, 2014, p. 12).

Se todos os indivíduos compartilham do mesmo substrato anímico, logo podemos afirmar que as afinidades em relação aos inúmeros mitos não sejam um acaso. Todos os seres humanos compartilham dos mesmos arquétipos, e esses arquétipos são os responsáveis pelo surgimento dos mitos, que inicialmente, são manifestações da essência da alma ${ }^{18}$. Graças ao processo de formação do mito ser inconsciente, os estudiosos em tudo pensaram, menos na própria alma. E embora seja válido um estudo mais abrangente acerca dos arquétipos em geral, dedicar-nos-emos ao arquétipo do herói, uma vez que é aquele assimilado a Augusto.

O herói na literatura é o centro da história narrada, o elo que nos une ao cosmos da obra; na mitologia, é o centro do mundo, aquele que faz com que o mundo gire de forma concisa; na religião, é o modelo ideal a ser seguido, aquele que é o humano ao exemplo do divino; na psicanálise, é o eu que almeja a harmonia do cosmos interior. O herói é então aquele que une e aquele que busca, aquele que passa pelas provações da vida e do caminho e que, em seu cerne, anseia pela etapa final do principium individuationis.

Têm-se como primordial na trajetória do herói o seu retorno com algum conhecimento adquirido - referenciado como elixir - em prol da reconstrução da perda inicial. O herói que

\footnotetext{
${ }^{18}$ Entende-se alma também como mente.
} 
não reconstrói seria egoísta, a ponto de desenvolver-se por nada além dele mesmo. Isso seria a quebra da questão coletiva, inviabilizando todo o pensamento fundamental do mito como produto do inconsciente coletivo. Tal caminho - ou como Campbell utiliza, jornada - do herói caracteriza-se pela presença de três atos bem construídos: o primeiro, que significa a separação e que Campbell nomearia por partida; o segundo ato denominado de iniciação e um terceiro ato chamado de retorno. Campbell ainda subdivide cada grande unidade em pequenos estágios, nem todos necessariamente fundamentais, sendo inclusive passíveis a variações. Joseph Campbell recapitula os estágios da jornada do herói resumindo-os da seguinte maneira:

O herói mitológico, saindo de sua cabana ou castelo cotidianos, é atraído, levado ou se dirige voluntariamente para o limiar da aventura. Ali encontra uma presença sombria que guarda a passagem. O herói pode derrotar essa força, assim como pode fazer um acordo com ela, e penetrar com vida no reino das trevas; pode, da mesma maneira, ser morto pelo oponente e descer morto. Além do limiar, então o herói inicia uma jornada por um mundo de forças desconhecidas e, não obstante, estranhamente íntimas, algumas das quais o ameaçam fortemente (provas), ao passo que outras lhe oferecem uma ajuda mágica (auxiliares). Quando chega ao nadir da jornada mitológica, o herói passa pela suprema provação e obtém sua recompensa. Seu triunfo pode ser representado pela união sexual com a deusa-mãe (casamento sagrado), pelo reconhecimento por parte do pai-criador (sintonia com o pai), pela sua própria divinização (apoteose), ou, mais uma vez - se as forças tiverem se mantido hostis a ele -, pelo roubo, por parte do herói, da benção que ele foi buscar (rapto da noiva, roubo do fogo); intrinsicamente, trata-se de uma expansão da consciência e, por conseguinte, do ser (iluminação, transfiguração, libertação). O trabalho final é o do retorno. Se as forças abençoarem o herói, ele agora retorna sob a sua proteção (emissário); se não for esse o caso, ele empreende uma fuga e é perseguido (fuga de transformação, fuga de obstáculos). No limiar do retorno, as forças transcendentais devem ficar para trás; o herói reemerge do reino de terror (retorno, ressureição). A benção que ele traz consigo restaura o mundo (elixir). (CAMPBELL, 2007, p. 240).

Analisando o personagem de Enéias sob a perspectiva monomítica proposta, nos depararemos com diversos aspectos que sustentam sua posição como herói característico do mito universal. O herói levado a sair de sua terra, dirigindo-se aos mares que caracterizam o limiar da aventura; vence a provação de Juno graças à intervenção de Vênus, assim como mantém incólume sua missão de conquistar o Lácio após a provação de amor com Dido; vence a morte ao voltar do mundo dos mortos, onde obtém a homologação por parte de seu pai, Anquises; ao chegar ao seu destino, passa pela provação última, a luta contra Turno, da qual sai vitorioso e recebe seu prêmio, consolidado pelo casamento com Lavínia; após toda a aventura, retorna para Troia com Lavínia e toda a sabedoria conquistada para restaurar sua 
terra. Fecha-se assim o ciclo característico da jornada, e ilustrando-o, o trecho a seguir mostra a saída do herói de Tróia, sintetizando, assim, o início da aventura.

Vamos, paizinho! Segura-te no meu pescoço e não caias.

Vou carregar-te nos ombros; brinquedo de criança é o teu peso.

Venha o que vier, corremos perigos iguais, pois para ambos

a salvação será a mesma. Ao meu lado acompanha-me Ascânio,

e pouco atrás a consorte me siga de perto, sem medo. (II, v. 707-711).

\section{CONCLUSÃO}

Os motivos da repercussão e circulação da Eneida à época de Augusto emaranham-se em um complexo de possibilidades interpretativas. Um novo viés, talvez, graças aos avanços no conhecimento da psicologia moderna, pode contribuir para analisarmos o efeito que tal obra tenha tido na época. Estudos recentes acerca dos mitos, das mentalidades, do consciente e do inconsciente ajudaram-nos a embasar teoricamente nossa argumentação sobre o período augustano.

Joseph Campbell, ao trazer sua teoria do monomito, possibilitou-nos trabalhar de forma interdisciplinar mito e história. Através de seus escritos fomos capazes de compreender melhor dois personagens distintos - Eneias e Augusto - e sustentar, sob viés da psicologia analítica, como a Eneida foi de suma importância para o estabelecimento e aceitação de Augusto como o princeps, ratificando que Virgílio foi não “apenas” um poeta, mas um agente vital para a construção daquilo que estava se formando, o imperium.

Virgílio enaltece um Eneias heroico - no sentido arquetípico da palavra - que representa o Augusto vivo, o representante do povo. Ao fazer essa analogia, era implícito que o herói Augusto passara por todas as provações em vida que seu ascendente - Eneias vivenciara. Augusto emergira, então, dos desafios como um príncipe reformado, aquele que levaria seus súditos a se tornarem os próximos heróis, seguindo os próprios passos de seu líder. Augusto alcançara o cerne do principium individuationis, tornando-se o modelo ideal de indivíduo, mostrando assim que era o mais preparado para defender os interesses de Roma. Augusto era o herói que completara seu ciclo, animicamente preparado, cantado pelo grande poeta, inspirado pelas musas. Virgílio cantava que Augusto era o piedoso, o civilizador, o unificador, o pai, o guerreiro, o piedoso, o pacificador, o líder, tudo isso sintetizado na pessoa que atingira o objetivo máximo em relação à completude da alma, o selbst.

Não é de se admirar que Augusto enxergava a si mesmo de forma especial, uma vez que ele descendia de César, tendo se tornado, naquele momento, o único e primeiro imperator 
da maior civilização conhecida da época. Mantinha a aura de possuir uma ascendência divina, vencera as guerras contra todos os seus rivais e conquistara várias terras almejadas pelos seus predecessores. Momento nenhum seria mais favorável para o concebimento da Eneida. Ela canta as grandes gestas dos ascendentes daquele que viera a ser o princeps civitatis de Roma, tal como valoriza sua tão enaltecida missão civilizadora.

Não obstante, não podemos nos esquecer de que a abordagem aqui proposta é uma dentre diversas possibilidades. É de vital importância perceber que a psicologia, enquanto estudo científico da mente e do comportamento, não era conhecida desta maneira pelo povo romano, logo essa abordagem é uma hipótese baseada em questões inconscientes. É uma abordagem audaciosa, uma vez que autores conhecidos na época da composição da Eneida, como Horácio e Aristóteles, compreendiam o gênero épico de forma diferente da aqui apresentada. O herói é representado como o símbolo uno dos conceitos de uirtus, pietas e fides, conceitos esses capitais para a sociedade romana. Esses valores eram de tamanha importância para o povo que se fazia fundamental que o príncipe os personificasse. Eneias, além de representar o caminho da jornada do herói de Augusto, mostrava que o imperador também possuía tais valores. Podemos perceber que a intersecção entre psicologia e literatura aqui apresentada serve para atualizar a leitura da história e da literatura, não para substituir modelos já aceitos sobre o período de Augusto.

\section{REFERÊNCIAS}

ALBERTIM, Alcione Lucena. Catábase de Eneias: um ato piedoso. João Pessoa: Centro de Ciências Humanas e Artes. Programa de Pós-Graduação em Letras. Universidade Federal da Paraíba, 2008.

ARISTÓTELES. Poética (bilíngue). Tradução: Paulo Pinheiro. São Paulo: Editora 34, 2017.

BARROS, José d’Assunção. “Teorias da História” e “Filosofias da História”: considerações sobre o contraste entre dois espaços de reflexão sobre o fazer história. Anos 90. Porto Alegre: v. 19, n. 36, p. 367-400, dez. 2012.

BARROS, José d’Assunção. História comparada. Petrópolis: Vozes, 2014.

BRANDÃO, Junito. Dicionário mítico-etimológico da mitologia e da religião romana. Petrópolis: Vozes, 1993.

BULFINCH, Thomas. Myths of Greece and Rome. New York: Penguin Books, 1981. 
CAMPBELL, Joseph. O herói de mil faces. Tradução: Adail Ubirajara Sobral. São Paulo: Pensamento, 2007.

DETIENNE, Marcel. Comparar o incomparável. Tradução: Ivo Storniolo. Aparecida: Idéias e Letras, 2014.

EYLER, Flávia Maria Schlee. História Antiga: Grécia e Roma: a formação do Ocidente. Petrópolis: Vozes; Rio de Janeiro: PUC-Rio, 2014.

GRIMAL, Pierre. História de Roma. Tradução: Maria Leonor Loureiro. São Paulo: Editora UNESP, 2010.

GRIMAL, Pierre. Virgílio ou o Segundo nascimento de Roma. Tradução: Ivone Castilho Benedetti. São Paulo: Martins Fontes, 1992.

JACOBI, Jolande. Complexo, arquétipo e símbolo na psicologia de C.G. Jung. Tradução: Margit Martincic. São Paulo: Cultrix, 1991.

JUNG, C. G. Os arquétipos e o inconsciente coletivo. Tradução: Maria Luiza Appy e Dora Mariana R. Ferreira da Silva. Petrópolis: Vozes, 2014.

JUNG. C. G. A interpretação psicológica do dogma e da trindade. Tradução: Mateus Ramalho Rocha. Petrópolis: Vozes, 2013a.

JUNG. C. G. O desenvolvimento da personalidade. Tradução: Frei Valdemar do Amaral. Vozes: Petrópolis, 2013b.

JUNG. C. G. Psicologia do inconsciente. Tradução: Maria Luiza Appy. Petrópolis: Vozes, 2014.

KOTHE, Flávio R. O herói. São Paulo: Ática, 1985.

MARQUES JUNIOR, Milton. Dicionário da Eneida, de Virgílio: livro I: Eneias na Líbia. João Pessoa: Ideia/Zarinha, 2011a.

MARQUES JUNIOR, Milton. Dicionário da Eneida, de Virgílio: livro II: a destruição de Troia. João Pessoa: Ideia/Zarinha, 2011b.

MARQUES JUNIOR, Milton. Dicionário da Eneida, de Virgílio: livro III: as errâncias de Eneias. João Pessoa: Ideia/Zarinha, 2012.

NAGY, Gregory. O herói épico. Coimbra: Imprensa da Universidade de Coimbra, 2017.

PEREIRA, Maria Helena da Rocha. Estudos de História da Cultura Clássica: volume II: cultura romana. Lisboa: Fundação Calouste Gulbenkian, 2013.

PIRES, Thiago Lourenço de Almeida Cardoso. A Construção moral do herói Enéias: como exemplo de vir romanvs na Roma Augustana. Dossiê História e Gênero, Rio de Janeiro, v. 24, p. 28-38, jan./jun. 2016.

RUSSO, Joseph. Manual de Cambridge para estudos junguianos. Tradução: Daniel Bueno. Porto Alegre: Artmed, 2002. 
SCHIMIDT, Joel. Dicionário de Mitologia Grega e Romana. Lisboa: Edições 70, 2002.

VIRGÍLIO. Eneida (bilingue). Tradução: Carlos Alberto Nunes. São Paulo: Editora 34, 2016. 